\title{
BMJ Open Overlap between child protection services and the youth justice system: protocol for a retrospective population- based cohort study using linked administrative data in Manitoba, Canada
}

\author{
Nathan C Nickel (DD , ${ }^{1}$ Lorna Turnbull, ${ }^{2}$ Elizabeth Wall-Wieler, ${ }^{3}$ Wendy Au, ${ }^{1}$ \\ Okechukwu Ekuma, ${ }^{1}$ Leonard MacWilliam, ${ }^{1}$ Jennifer Emily Enns (D) , \\ Janelle Boram Lee, ${ }^{1}$ Scott McCulloch, ${ }^{1}$ Charles Burchill, ${ }^{1}$ Marni Brownell ${ }^{1}$
}

To cite: Nickel NC, Turnbull L, Wall-Wieler E, et al. Overlap between child protection services and the youth justice system: protocol for a retrospective populationbased cohort study using linked administrative data in Manitoba, Canada. BMJ Open 2020;10:e034895. doi:10.1136/ bmjopen-2019-034895

- Prepublication history and additional material for this paper are available online. To view these files, please visit the journal online (http://dx.doi. org/10.1136/bmjopen-2019034895).

Received 09 0ctober 2019 Revised 14 February 2020 Accepted 29 May 2020

D) Check for updates

(c) Author(s) (or their employer(s)) 2020. Re-use permitted under CC BY-NC. No commercial re-use. See rights and permissions. Published by BMJ.

For numbered affiliations see end of article.

Correspondence to Dr Nathan C Nickel; Nathan_Nickel@cpe.umanitoba. ca

\section{ABSTRACT}

Introduction Children who have a history of involvement in child protection services (CPS) are over-represented in the youth and adult criminal justice systems. There are significant health and socioeconomic implications for individuals involved in either or both CPS and the justice system. Understanding the 'overlap' between these two systems would provide insight into the health and social needs of this population. This protocol describes a research programme on the relationship between the child welfare and the youth justice systems, looking specifically at the population involved in both CPS and the youth justice system. We will examine the characteristics associated with involvement in these systems, justice system trajectories of individuals with a history of CPS involvement and early adult outcomes of children involved in both systems.

Methods and analysis Administrative data sets will be linked at the individual level for three cohorts born 1991, 1994 and 1998 in Manitoba, Canada. Involvement in CPS will be categorised as 'placed in out-of-home care', 'received in-home services, but was not placed in care' or 'no involvement'. Involvement in the youth justice system will be examined through contacts with police between ages 12 and 17 that either led to charges or did not proceed. Individual, maternal and neighbourhood characteristics will be examined to identify individuals at greatest risk of involvement in one or both systems. Ethics and dissemination The study was approved by the University of Manitoba Health Research Ethics Board and permission to access data sets has been granted by all data providers. We also received approval for the study from the First Nations Health and Social Secretariat of Manitoba's Health Information Research Governance Committee and the Manitoba Metis Federation. Strategies to disseminate study results will include engagement of stakeholders and policymakers through meetings and workshops, scientific publications and presentations, and social media.
Strengths and limitations of this study

- The study uses linked administrative data on child/ youth involvement in child protection services and youth criminal justice system for the entire population (>99\%) of the Canadian province of Manitoba.

- Using administrative data minimises the risks for bias due to differential recall, loss to follow-up and/ or selection bias which are common threats to survey research in this area.

- We have integrated knowledge users, including policymakers, representatives from the community, and child and youth advocates, into our research process to strengthen the impact that our study will have on identifying and resolving systemic barriers in child welfare and the youth justice system.

- Although we plan to adjust our statistical models for variables such as socioeconomic status, residential mobility, urbanicity, mental health comorbidities and family-level characteristics, there is still some potential for unmeasured confounding in this study because of information we do not have access to (including, for example, full histories of parental criminal justice system involvement).

- We lack data on systemic and structural factors that predispose some children over others to become involved with either and/or both systems-such as systemic racism and ongoing colonial laws and policies.

\section{INTRODUCTION}

Over the past few decades, there has been much scholarly interest in the association between involvement in child protection services (CPS; eg, placement in out-of-home or foster care, and/or receiving in-home services) and later involvement in the youth criminal justice system. In both Canada and 
the USA, several studies have reported a sizeable overlap in the population that has been in contact with both CPS and the youth justice system. For example, in a Canadian population-based cohort study, $17 \%$ of children and youth placed in care had also been taken into custody, and $41 \%$ had a record of charges in the youth justice system with offences including assault and propertyrelated crimes. ${ }^{1}$ In a US sample of young adults who had previously been in care, $28 \%$ reported that they had been arrested and $19 \%$ reported spending at least one night in a correctional facility. ${ }^{2}$ Similar overlaps between CPS and the youth justice system have also been documented in jurisdictions such as Australia and New Zealand..$^{3-7}$

Several correlates of CPS and youth justice system involvement have been previously identified in the literature. Although males in the USA have higher rates of youth justice system involvement than females, a history of being involved in CPS increased the risk of youth justice system involvement more for females than males. ${ }^{8}$ Another US study showed that African-American and Hispanic children with a history of being in care were at higher risk of youth justice system involvement after they returned home from care, while for Caucasian children, the risk was lower after they returned home. ${ }^{9}$ A child's age at entry into out-of-home care has also been shown to influence justice system outcomes: entering care between the ages of 13 and 18 was a strong predictor for later involvement in the criminal justice system among male youth, but for males first placed in care before the age of 13 (and for females in either age group), there was no relationship with justice system outcomes. ${ }^{10}$ Previous episodes of maltreatment, such as experiencing neglect or being the victim of physical or sexual abuse, as well as having a history of mental illness, have also been linked to increased risk of incarceration among children and youth in families with previous CPS involvement. ${ }^{911}$

The overlap between CPS and the youth justice system and the variables related to this overlap are of particular troubling in relation to indigenous youth in Canada, given the degree to which this population is over-represented in both systems. In 2016, just over half of children involved in CPS $^{12}$ and one-third of youth involved in the youth justice system were indigenous, ${ }^{1}$ despite indigenous children comprising only $7.7 \%$ of the total child population in Canada. ${ }^{13}$ These statistics reflect a multitude of social and economic issues faced by Canadian indigenous families, but key among them is the harm perpetrated by centuries of colonial policies. The residential school system and the 'Sixties Scoop' systematically separated indigenous children from their families and communities, cutting them off from their caregivers, their languages and their cultural identities in an effort to assimilate them into a colonial western sociocultural landscape. ${ }^{14-16}$ The formal inquiry into these practices by the Truth and Reconciliation Commission of Canada (TRCC) has concluded that they constituted a form of cultural genocide, ${ }^{17}$ and the suffering they inflicted on multiple generations of indigenous peoples continues to this day. ${ }^{16}$ The same indigenous families devastated by Canada's residential school system are being separated from their children by CPS policies, and the resulting loss of family and community ties is perpetuating a destructive cycle of socioeconomic disadvantage, which includes low levels of education, high levels of unemployment, poverty, inadequate housing and health disparities. ${ }^{18}$ There is also evidence that racial discrimination plays a role in the large number of indigenous children in care. Child welfare agencies with higher numbers of indigenous children in their case loads have access to fewer resources, ${ }^{19} 20$ and receive funding top-ups only at the cost of reduced support for resources like housing and infrastructure. The reallocation of funds from housing, water and sanitation to address shortfalls in CPS places children at higher risk of needing these services in the first place, since poor housing is one of the key factors leading to children being taken into care. ${ }^{21}$ But even when controlling for poverty-related risk factors, indigenous children are still more likely than non-indigenous children to be taken into care of CPS. ${ }^{22} 23$

Policymakers, youth advocates and researchers are especially alarmed by the population of young people who are involved in CPS and the youth justice system and about the over-representation of indigenous children and youth in both systems. But while there is a convincing body of evidence linking the child welfare system and the youth justice system, this literature is unable to support meaningful policy change for a number of reasons. Most published studies have small sample sizes and uncertain representation from the general Canadian population, ${ }^{2}$ and studies focusing specifically on indigenous youth are still lacking. There is no standard definition for 'youth involvement in the criminal justice system' and so this measure varies widely across studies. ${ }^{11}$ There is also strong potential for sampling bias in many previously published studies. ${ }^{2} 81124$ Our research programme will strive to address these limitations by using whole-population administrative records on healthcare system use, social services use (eg, CPS), education system outcomes and youth justice system involvement to identify and characterise the population involved in both CPS and the youth justice system. Our research programme aims to begin addressing the TRCC's Calls to Action to reduce the number of indigenous children in care $^{16}$ and eliminate the over-representation of indigenous youth in custody by reporting the number of children affected and identifying characteristics that put them at risk.

The major advantages of using administrative data for this type of longitudinal research include: access to continuously recorded data, allowing us to examine the effects of policy changes over time without the measurement and loss to follow-up biases often associated with longitudinal surveys ${ }^{25-27}$; the ability to take individual and family characteristics into account by linking administrative records at these levels ${ }^{28}$; and in the unique case of Manitoba where an enormous breadth and depth of administrative data are available, the ability to place the research in the 
context of the social determinants of health and conduct area-level comparisons between specific populations of interest. ${ }^{26}{ }^{27} \mathrm{~A}$ better understanding of the relationships between CPS, the youth justice system, and the health, social and education consequences for individuals who are involved in both systems will inform laws, policies, programmes and practices to better support vulnerable children and youth in Canada and elsewhere.

The four key research objectives, and related hypotheses, of this project are:

1. To quantify the overlap between involvement in CPS and the youth justice system.

2. To identify the characteristics associated with involvement in CPS and/or the youth justice system:

Hypothesis 2a: We hypothesise that the following characteristics will be associated with an increased likelihood for a child becoming involved with CPS, the youth justice system and involvement with both systems: biological sex of the child, lower socioeconomic status of the mother, diagnosed mental disorders in the mother and diagnosed mental disorder in the child (prior to involvement with CPS).

Hypothesis 2b: We hypothesise that indigenous identity will operate as an effect modifier of these associations (due to ongoing colonial laws and policies, systemic and structural racism, and enduring legacies of practices such as the Sixties Scoop and residential schools). Hypothesis 2c: We hypothesise that year of birth will operate as an effect modifier due to the implementation of policies such as the Youth Criminal Justice Act (YCJA).

3. To examine different trajectories through the youth justice system among children with a history of CPS involvement:

Hypothesis 3a: We hypothesise that the following characteristics among children with a history of CPS involvement will be associated with increased rates of being charged with a crime: being male, being placed in out-of-home care (vs receiving services from CPS), younger age at first involvement with CPS, having more placements, being placed in group home and child having diagnosed mental disorders.

Hypothesis 3b: We hypothesise that the following characteristics among children with a history of CPS involvement will be associated with a decreased likelihood of the child having their charge deferred: being placed in out-of-home care (vs receiving services from CPS), group home placement, age at first involvement with CPS and child having diagnosed mental disorders.

Hypothesis $3 c$ : We hypothesise that the following characteristics will operate as effect modifiers of these relationships: birth year (due to policies such as the YCJA), urbanicity (due to fewer diversion services being available to youth living in rural areas) and indigenous identity.

4. To examine the early adult health, social, education and justice outcomes of individuals involved in CPS and the youth justice system:
Hypothesis 4a: We hypothesise that individuals who are involved with both CPS and the youth justice system will have poor physical and mental health outcomes, and poorer social and education outcomes, and greater criminal justice involvement during early adulthood when compared with those children who are involved with only one or neither system.

Hypothesis 4b: We hypothesise that the following characteristics will operate as effect modifiers of these associations: indigenous identity, birth year and urbanicity.

\section{METHODS AND ANALYSIS \\ Context}

This programme of research uses administrative data from the central Canadian province of Manitoba (population $\sim 1.3$ million). Manitoba is generally representative of the broader Canadian population across numerous health and education indicators, ${ }^{29}$ but has the highest rate of children being taken into care in Canada (and higher than other developed countries), as well as the highest youth incarceration rate in Canada. ${ }^{30}$ Ethics approvals and data access permissions were obtained in April 2017; we began deriving and validating new variables in the administrative data in May 2017, and we expect the planned analyses to be completed by April 2021.

\section{Patient and public involvement}

As this programme of research uses routinely collected administrative data to examine cohort characteristics and outcomes, we do not expect to have any direct patient involvement. However, we have sought the input and expertise of knowledge users and stakeholders from the start of the research programme onwards to ensure the findings are relevant for these groups. Our indigenous partners include representatives from the Manitoba First Nations Family Advocate Office, the Manitoba Child and Family Services Standing Committee, the First Nations Health and Social Secretariat's Health Information Research Governance Committee, the Manitoba Metis Federation, and an advisory group for the programme of research comprising representatives from the aforementioned groups as well as the Assembly of Manitoba Chiefs' Grandmothers Council, the Winnipeg Police Service, provincial government departments (Manitoba Justice, Manitoba Families, Healthy Child Manitoba), the Manitoba Advocate for Children and Youth, the Manitoba Child and Family Services Authorities, and the Southern Chiefs' Organization. The advisory group meets with the research team at least once annually to provide guidance and context on the preliminary work, and has begun discussing the research findings as they become available. Representatives from the First Nations Family Advocate Office have generously spent additional time with the study team, including laying the groundwork for a workshop with a youth advisory group, to provide context to the myriad structural and social forces affecting the study cohort; they will work with us to ensure that an indigenous 
lens is applied to the interpretation of research findings. Our goal in engaging this group of stakeholders is to ensure that their perspectives and experiences are represented in the work and that our findings address the most critical issues in a culturally sensitive way.

\section{Data sources}

Administrative data for this programme of research are derived from the Manitoba Population Research Data Repository at the Manitoba Centre for Health Policy, University of Manitoba. The deidentified data sets in the Repository contain health, social, education and justice data on over $99 \%$ of the Manitoba population, and are linkable at the individual and familial levels using a scrambled personal identifier. Table 1 lists the data sets that we will use to derive and validate the required variables and complete the planned analyses.

\section{Variables}

\section{Child protection services}

Children who are 'in care of CPS' have been removed from the care of their family of origin because they are believed to be in need of protection under the Child and Family Services Act. ${ }^{32}$ The Child and Family Services Act defines a child in need of protection as one whose life, health or emotional well-being is endangered. Children may be taken into care for a variety of reasons, including abuse and/or neglect, addiction issues, conflict in their family, disability, parental illness, or death of parent, or they may be voluntarily placed into care by their parents or guardians. The amount of time children spend in care is highly variable-some may only be away from their families for short time, while others may spend many years in care, and still others are never returned to their family of origin. Care may be provided by approved relatives, state-supported foster families or in-group settings. Children in care do not include children who remain with or are returned to a parent or guardian under an order of supervision.

In Manitoba, information on children in care of CPS is collected by the Department of Families, Child and Family Services Division. Table 2 lists the variables we will measure relating to a child's involvement in CPS. More information on the legal status of out-of-home placement and the reason for admission to out-of-home care is presented in online supplementary table S1.

\section{Youth criminal justice system}

Canadian youth aged 12-17 who become involved in the criminal justice system are charged under the provisions of the Criminal Code ${ }^{33}$ Until 2003, youth involvement in the justice system was governed by the Young Offenders Act, ${ }^{34}$ under which Canada had the highest rates of youth incarceration among Western nations. ${ }^{35}$ The Young Offenders Act was then replaced by the YCJA, ${ }^{36}$ which focuses on prevention and accountability. The YCJA encourages the use of corrective measures outside of the formal court system for less serious offences in recognition that young people have different developmental needs and capacities than adults. As implementation of the YCJA evolved over the subsequent years, the case loads of youth courts declined by $26 \%$ and the overall rates and severity of youth crimes also decreased. These rates have continued to decline over the decade and a half since the YCJA came into force, and this pattern should be evident in our research: our study population reached the age of 12 at the time the YCJA was introduced. For serious offences, separate youth courts within the formal court system handle charges against youth. A judge determines the appropriate sentence from options different from those stipulated for adults in the Criminal Code, although they may also choose to sentence a young person as an adult when they think it warranted. However, youth cannot be admitted to an adult prison before the age of 18 .

In Manitoba, information on criminal justice system involvement is collected through the Prosecution Information Management Network, which contains data on the type of incidents and type of involvement (eg, whether the individual involved was accused of a crime, a victim of a crime or a witness to a crime). For those accused of a crime, involvement is further classified into 'proceeding' or 'not proceeding/undetermined', and specific charges are grouped into categories (table 3). For details on the specific section of the acts and regulations under which each charge category falls, see online supplementary table S2.

\section{Health, social and education variables}

We will link health, social and education variables to CPS and justice system data sets to provide additional context for the 'overlap' findings (table 4). The characteristics of CPS and youth justice system-involved children and their families will help us understand the social and economic circumstances in which these individuals lived and provide more details on the factors contributing to their involvement in CPS and in the youth justice system.

\section{Cohorts}

We will define three birth cohorts (starting in 1991, 1994 and 1998) to examine CPS and youth justice system involvement over time and in different stages of adolescence and early adulthood. The 1991 birth cohort allows us to examine youth justice system involvement, as well as other outcomes in young adulthood (from ages 18 to 24); since Manitoba's CPS data collection began in 1992, information on very early childhood out-of-home care will not be entirely complete for this cohort. The 1994 and 1998 birth cohorts will have complete information on CPS involvement from birth to age 18. The 1994 and 1998 birth cohorts will also have justice system data available to ages 21 and 18, respectively. Multiple birth cohorts will be analysed separately to identify changes between periods.

As shown in figure 1, we will initially include in each cohort all individuals born in that year who were registered at some point for health insurance. We will then exclude individuals with a Manitoba Health registration 
Table 1 Description of data sources

\section{Data set name and} domain

Health Manitoba Health Insurance Registry

\begin{tabular}{|c|c|}
\hline $\begin{array}{l}\text { Hospital Discharge } \\
\text { Abstracts }\end{array}$ & $\begin{array}{l}\text { Health data maintained by Manitoba } \\
\text { Health, Seniors and Active Living } \\
\text { consisting of all hospitalisations in } \\
\text { Manitoba }\end{array}$ \\
\hline Provider Registry & $\begin{array}{l}\text { Maintained by Manitoba Health, Seniors } \\
\text { and Active Living, includes details about } \\
\text { physicians and nurse practitioners and } \\
\text { their practices }\end{array}$ \\
\hline Medical Services & $\begin{array}{l}\text { Health data maintained by Manitoba } \\
\text { Health, Seniors and Active Living } \\
\text { consisting of all ambulatory physician } \\
\text { visits in Manitoba }\end{array}$ \\
\hline $\begin{array}{l}\text { Drug Program } \\
\text { Information Network Data }\end{array}$ & $\begin{array}{l}\text { Data maintained by Manitoba Health, } \\
\text { Seniors and Active Living consisting of } \\
\text { information on all prescription drugs } \\
\text { dispensed in Manitoba }\end{array}$ \\
\hline $\begin{array}{l}\text { Manitoba Fetal Alcohol } \\
\text { Spectrum Disorder }\end{array}$ & $\begin{array}{l}\text { Maintained by Winnipeg Health } \\
\text { Authority; includes clinical assessments } \\
\text { and diagnoses received under the FASD } \\
\text { umbrella for all children referred to the } \\
\text { Manitoba FASD Centre }\end{array}$ \\
\hline
\end{tabular}

Social

A registry maintained by Manitoba Health, Seniors and Active Living of all Manitobans eligible to receive health services

\section{Description}

\section{Data available* Information retrieved}

1970/1971-

2016/2017

1970/1971$2016 / 2017$

(2016/2017

\section{Births, deaths, coverage status, sex, location of residence, marital and family status}

Hospitalisations, diagnoses, procedures, services, providers, length of stay, hospital and case characteristics

Specialty type of physicians providing services

$1980 / 1981-$ $2016 / 2017$

1995/1996$2016 / 2017$

1999-2016

Services, diagnoses, facility, location, group, physician characteristics

Prescriptions, drug characteristics (eg, type, dose, quantity, class), carriers, prescribers, providers, pharmacy

Services received in the FASD programme

Social Allowance
Management Information
Network
Network

Data maintained by Manitoba Families that provides information on Manitoba residents who receive provincial employment and income assistance (EIA)

Tenant Management System

\section{Maintained by Manitoba Housing,} Department of Families, provides details on all households living in units managed by Manitoba Housing

\section{5/1996- \\ Receipt of EIA: date, duration, type} 2016/2017

1995/1996$2016 / 2017$

Household type, length of stay, location, and so on

Intake information, length of episode of care, number of episodes, placement type, legal status, reason for admission, support beyond termination of guardianship, services received

1996, 2001, 2006, Community-level data on key 2011, 2016† socioeconomic characteristics

Canadian Census (public Social data based on the Statistics use file) Canada Population Census

Education

Enrollment, Marks, and Education data maintained by Manitoba 1995/1996Assessments Education and Training that provides 2016/2017

Enrolment, marks, standard tests, teacher assessment, and so on information on enrolment, marks, assessments and special funding

Justice system

Criminal Courts Automated Information Network (CCAIN)
Maintained by Manitoba Justice; contains records of criminal court appearances and criminal charges relating to each case. 


\begin{tabular}{|c|c|c|c|}
\hline $\begin{array}{l}\text { Data set name and } \\
\text { domain }\end{array}$ & Description & Data available* & Information retrieved \\
\hline $\begin{array}{l}\text { Prosecutions Information } \\
\text { and Scheduling } \\
\text { Management (PRISM) }\end{array}$ & $\begin{array}{l}\text { Data management system maintained } \\
\text { by Manitoba Justice including } \\
\text { information on incidences, charges and } \\
\text { involvements in the justice system in } \\
\text { Manitoba }\end{array}$ & 2002-2017 & $\begin{array}{l}\text { Incident type, charges, disposition, } \\
\text { warrants, calls for service, crime and } \\
\text { crime type }\end{array}$ \\
\hline \multicolumn{4}{|l|}{ Registries } \\
\hline $\begin{array}{l}\text { Manitoba First Nations } \\
\text { Research File }\end{array}$ & $\begin{array}{l}\text { Registry of Manitoba First Nations } \\
\text { people registered as Status Indians } \\
\text { under the Federal Indian Act, generated } \\
\text { from the federal government Indian } \\
\text { Status Registry as of } 2016 \text {, and } \\
\text { provided to Manitoba Centre for Health } \\
\text { Policy (MCHP) by the First Nations } \\
\text { Health and Social Secretariat of } \\
\text { Manitoba }\end{array}$ & 1980-2018 & $\begin{array}{l}\text { Fields related to First Nations } \\
\text { identity }\end{array}$ \\
\hline Metis Registry & $\begin{array}{l}\text { A membership list maintained by the } \\
\text { Manitoba Metis Federation }\end{array}$ & 1990-2016 & Fields related to Metis identity \\
\hline
\end{tabular}

${ }^{*}$ Fiscal year (1 April to 31 March).

†Calendar year (1 January to 31 December).

FASD, fetal alcohol spectrum disorder.

error, and those who did not live in Manitoba at some point between ages 12 and 17. After exclusions, each cohort is expected to include between 15000 and 20000 individuals.

\section{Analysis plan}

Objective 1: quantify the overlap between involvement with CPS and the youth justice system

We will first create a set of three dichotomous indicators:

1 . The youth had a criminal charge recorded in the justice system data before their 18th birthday (yes/no).

2. The index child's family was involved in CPS, but the child/youth was never placed in out-of-home care prior to having a criminal charge recorded as a youth or young adult (yes/no) (all children in family that received services will be classified as having received services and analyses will account for clustering at the family level).

3. The child/youth spent at least 1 day in the care of CPS prior to any criminal charge as a youth or young adult (yes/no).

A child with 'no' on all four indicators will have had no contact at all with CPS or the youth justice system. We will use these four indicators to construct categorical variables which will summarise each child's level of involvement with CPS and/or the youth justice system. The six possible categorical variables of interest describing level of involvement are shown in table 5 .

Objective 2: identify the characteristics associated with involvement in CPS and/or the youth justice system

We will test whether the following characteristics are associated with an increased likelihood for a child to be involved with CPS, involvement with the youth justice system and involvement with both systems: lower socioeconomic status of the mother, diagnosed mental disorders in the mother, physical health of the mother, diagnosed mental disorder in the child (prior to involvement with CPS) and physical health of the child (prior to CPS involvement). We will first generate descriptive statistics comparing the characteristics of each group and use $\chi^{2}$ tests and t-tests to identify statistically significant differences between them. We will also generate a multivariable multinomial regression model-with the different categories of system involvement as the outcome-to test our hypothesis. Interaction terms with indigenous identity and birth year will be used to test whether these characteristics operate as effect modifiers.

Objective 3: examine different trajectories through the youth justice system among children with a history of CPS involvement

We will examine the different trajectories of children being processed in the youth justice system based on their involvement in CPS. Children will be classified into one of three groups:

1. Spent at least 1 day in out-of-home care prior to any charge.

2. Family involved in CPS prior to any charge, but the child is not in out-of-home care.

3. Family had no contact with CPS.

A child's status in these three groups will be treated as a time-varying covariate. For example, a child will be able to move from having no contact ${ }^{3}$ to being involved in CPS $^{2}$ to out-of-home care. ${ }^{1}$ The follow-up time for groups 1 and 2 will begin on the date when the child was taken into 
Table 2 Child protection services variables

\begin{tabular}{|c|c|}
\hline Variable & Definition \\
\hline Length of episode of care & $\begin{array}{l}\text { Episode of care refers to the time that a child is in care of CPS; if a child leaves CPS } \\
\text { care and then re-enters within } 7 \text { days, it is considered one episode. }\end{array}$ \\
\hline Placement type & $\begin{array}{l}\text { The type of care in which the child was placed: } \\
\text { Foster home } \\
\text { Foster home-specialised } \\
\text { Foster home-group home } \\
\text { Kinship care } \\
\text { Place of safety } \\
\text { Adoption probation } \\
\text { Unknown }\end{array}$ \\
\hline Reason for admission & $\begin{array}{l}\text { Reason for the child entering care of CPS: } \\
\text { Abandonment } \\
\text { Desertion } \\
\text { Conditions of child } \\
\text { Conditions of parents } \\
\text { Conduct of child } \\
\text { Conduct of parents } \\
\text { Voluntary relinquishment } \\
\quad \text { Transfer supervision }\end{array}$ \\
\hline $\begin{array}{l}\text { Support beyond termination of } \\
\text { guardianship }\end{array}$ & $\begin{array}{l}\text { An agency continues to provide care and maintenance for a former permanent ward for } \\
\text { the purpose of assisting the ward to complete the transition to independence, between } \\
\text { the ages of } 18 \text { and } 21 \text { years. }\end{array}$ \\
\hline Received services & $\begin{array}{l}\text { A family receives protection or support services from CPS, but the child remains in their } \\
\text { home of origin. These services are provided to resolve family matters, and may include } \\
\text { counselling, guidance, support, education and emergency shelter services. }\end{array}$ \\
\hline
\end{tabular}

CPS, child protection services.

care and the date when the child's family first became involved in CPS, respectively. Children from group 4 will be matched 1:5 to children in groups 1 and 2 based on sex, birth date $( \pm 3$ months) and postal code of residence at the time when the child was taken into care or first became involved in CPS, respectively.

The rate of youth justice system charges will be calculated from the time the child was taken into care (for group 1), the time the child's family first became involved in CPS (for group 2) or from the date that the child was matched (for group 3). Children will be followed until the day before their 18th birthday, or until they leave the province. Charges will be counted as the number of unique incidents (or unique interactions with the justice system) and as the number of individual charges against the child. For example, a child may have had one interaction with the youth justice system on 1 September 2018, but that interaction resulted in two individual chargesfor example, assault and drug possession. We would count this as a single incident and as two charges.

We will use multilevel generalised linear models (GLM) with a $\log$ population offset and the appropriate distribution (eg, Poisson, binomial, negative binomial, depending on the data) to calculate the rate of youth justice system charges for each group and to test our stated hypotheses. Involvement in CPS will be treated as a time-varying 
Table 3 Criminal justice system variables

Variable Definition

Type of involvement The following involvement types were defined as 'Accused':

- Accused

- Cautioned/warned

- Co-accused

- Crown opinion

- Crown caution

- No charges laid

- Intoxicated Persons Detention Act (IPDA)

- Warrant, cautioned (Youth Criminal Justice Act)

- Referred to a community programme (Youth Criminal Justice Act)

- No action taken (Youth Criminal Justice Act)

- Warned (Youth Criminal Justice Act)

The following involvement types were defined as 'Victim':

- Complainant

- Protected person

- Victim

- Deceased victim

The following involvement types were defined as 'Witness':

- Eye witness

- Material witness

- Witness

Charges Charges were grouped into the following categories:

- Violent

- Property

- Administrative

- Liquor Control Act

- Automobile theft

- All others (regulatory)

- Highway Traffic Act leading to a criminal conviction

- Highway Traffic Act offences

- No charge (included here are blank entries and any entry ending in no charge laid, discharged, stayed, crown opinion, pending)

Charge type charge is classified as 'proceeding' if the charge type ends in any of the following words/phrases:
A
A charge is classified as 'not proceeding' if the charge type ends in any of the following words/phrases:
Crown appeal
No charge laid
Precharge, precharge diversion
Discharged
Stayed
Crown opinion, crown opinion diversion


Table 4 Health, social and education variables

\begin{tabular}{ll}
\hline Variable & Definition \\
\hline $\begin{array}{l}\text { Mother's characteristics } \\
\text { Maternal age at first birth }\end{array}$ & Defined using the Manitoba Health Insurance Registry. Mother's age at the birth of her first child. \\
Marital status & $\begin{array}{l}\text { Defined using Families First/Babies First Screening Data and the Manitoba Health Insurance Registry. Three } \\
\text { categories: married/partnered, lone parent, or unknown. }\end{array}$ \\
Substance use disorder & Two data sources were used to define substance use disorders: \\
& 1. Medical Services/Physician Claims Data \\
& 2. Hospital Abstracts Data \\
& ICD-9-CM codes (before 1 April 2004): 291, 292, 303, 304, 305 \\
& ICD-10-CA codes (after 1 April 2004): F10-F19, F55
\end{tabular}

Mental disorders
1. Medical Services/Physician Claims Data
2. Hospital Abstracts Data
ICD-9-CM codes (before 1 April 2004): 290-319
3. ICD-10-CA codes (after 1 April 2004): F00-F99
- ATC codes starting with N06

Education

Defined using Families First/Babies First Screening Data and Enrollment, Marks, and Assessments Data from Manitoba Education. Three categories: less than grade 12, grade 12 or above, or unknown.

Receipt of employment and Defined using data from the Social Assistance Management Information System as at least 2 consecutive months of income assistance EIA receipt in a specified time period.

Income quintile of neighbourhood

Defined using the information from the Canada Census. Quintiles are based on dissemination area-level average household income values from the census. Income quintiles are first divided into urban (Winnipeg and Brandon) and rural (all other Manitoba areas), and then divided into five groups (quintiles), with approximately $20 \%$ of the population in each group.

\section{Child's characteristics}

Indigenous identity

Defined using the Manitoba First Nations Research File and Manitoba Metis Registry. Three categories-First Nations, Metis, All Others*.

Major illness

We will group physician visits and hospitalisations into Aggregated Diagnosis GroupsTM (ADGs-TM) codes for risk adjustment using the Johns Hopkins Adjusted Clinical Group(R) (ACG(R)) Case-Mix System version 10. These are defined using Medical Services/Physician Claims Data and Hospital Abstracts Data. If in a specified time period, a child has one of the following $A D G s^{37}$ :

ADG 3: time limited: major

ADG 9: likely to recur: progressive

ADG 11: chronic medical: unstable

ADG 12: chronic specialty: stable-orthopaedic

ADG 13: chronic specialty: stable-ear, nose, throat

ADG 18: chronic specialty: unstable-eye

ADG 25: psychosocial: recurrent or persistent, unstable

ADG 32: malignancy

Injuries

Defined using Hospital Abstracts Data:

- ICD-9-CM codes (before 1 April 2004): codes beginning with $E$

- ICD-10-CA codes (after 1 April 2004): codes beginning with V, W, X, Y

Mental disorders

Two data sources were used to define mental disorders:

1. Medical Services/Physician Claims Data

- ICD-9-CM codes: 290-319

2. Hospital Abstracts Data

- ICD-9-CM codes (before 1 April 2004): 290-319

- ICD-10-CA codes (after 1 April 2004): F00-F99

3. Drug Program Information Network

- ATC codes starting with N06 


\section{Table 4 Continued}

\begin{tabular}{|c|c|}
\hline Variable & Definition \\
\hline \multirow[t]{3}{*}{ Developmental disabilities } & Four different data sources were used to define developmental disorders: \\
\hline & 1. Medical Services/Physician Claims Data \\
\hline & ICD-9-CM codes: 317, 318, 319, 299 \\
\hline
\end{tabular}

2. Hospital Abstracts Data

- ICD-9-CM codes (before 1 April 2004): 317, 318, 319, 299

- ICD-10-CA codes (after 1 April 2004): F70.0, F70.1, F70.8, F70.9, F71.0, F71.1, F71.8, F71.9, F72.0, F72.1, F72.8, F72.9, F73.0, F73.1, F73.8, F73.9, F78.0, F78.1, F78.8, F78.9, F79.0, F79.1, F79.8, F79.9, F84.0, F84.1, F84.3, F84.4, F84.5, F84.8, F84.9, Q86.1, Q86.2, Q86.8, Q87.0, Q87.1, Q87.2, Q87.3, Q87.5, Q87.8, Q89.8, Q90.0, Q90.1, Q90.2, Q90.9, Q91.0, Q91.1, 91.2, Q91.3, 91.4, Q91.5, 91.6, Q91.7, Q93.0, Q93.1, Q93.2, Q93.3, Q93.4, Q93.5, Q93.6, Q93.7, Q93.8, Q93.9, Q99.2

3. Enrollment, Marks, and Assessments Systems and Technology Services / Instruction, Curriculum and Assessment Branch (STS/ICAB) (STS/ICAB) Data: the Special Needs File in the education data was used to identify children receiving funding for special needs. Children with developmental disorders were identified by a value of 'MH' or 'ASD' in the CATEGORYN variable.

The data also contain a variable (STATUSN) that describes whether the funding is approved, denied, non-supportable or terminated, and works in conjunction with CATEGORYN. Only those with an 'approved status' were included in the selection process.

5. Manitoba FASD Data: individuals were included if they had any of the following values in the variable $D I A$ Diagnosis: ARCB, ARND, ARND/ARBD, FAS, FAS/ARBD, or pFAS.

\begin{tabular}{|c|c|}
\hline Teen pregnancy & $\begin{array}{l}\text { Defined using Hospital Discharge Abstracts Data: } \\
\text { ICD-9-CM diagnosis codes (before } 1 \text { April 2004): V27, 632-637, 656.4 } \\
\text { ICD-10-CA diagnosis codes (after } 1 \text { April 2004): Z37, O02.1, O00, O03-O07, O36.4 } \\
\text { ICD-9-CM procedure codes (before } 1 \text { April 2004): 69.01, 69.51, 74.91, 66.62, 74.3, } 75.0 \\
\text { CCI codes (after } 1 \text { April 2004): 5.CA.89, 5.CA.90, 5.CA.93, 5.CA.88, 5.MD.5, 5.MD.60 }\end{array}$ \\
\hline High school completion & $\begin{array}{l}\text { Defined using Enrollment, Marks, and Assessments Data } \\
\text { A graduation flag in the 'Year End Status' variable in the student marks data OR } \\
\text { Student earned } 30 \text { or more credits between grades } 9 \text { and } 12 \text { OR } \\
\text { Student earned six or more grade } 12 \text { credits during high school }\end{array}$ \\
\hline
\end{tabular}

Employment and income assistance (ie, welfare or social assistance) is a programme of financial assistance for individuals who need help meeting the basic personal family needs, and thus serves as a measure of poverty.

${ }^{*}$ There are three major indigenous groups in Canada: First Nations, Metis and Inuit. There is currently no way of identifying Inuit children in the Manitoba Population Research Data Repository, and so Inuit children and youth are categorised with 'All Other Manitoba Children' in this research. Inuit children comprised less than $0.1 \%$ of the Manitoba child population in 2006 . $^{38}$

ADG, aggregated diagnostic group; ARBD, alcohol-related birth defect; ARND, alcohol-related neurodevelopmental disorder; ASD, autism spectrum disorder; ATC, Anatomical Therapeutic Chemical; CCI, Canadian Classification of Health Interventions; EIA, employment and income assistance; FAS, fetal alcohol syndrome; FASD, fetal alcohol spectrum disorder; ICD-10-CA, International Classification of Diseases, 10th Revision, Canadian Adaptation; ICD-9-CM, International Classification of Diseases, Ninth Revision, Clinical Modification; MH, multiple handicaps; pFAS, partial fetal alcohol syndrome; STS/ICAB, Systems and Technology Services / Instruction, Curriculum and Assessment Branch.

covariate in the models. A preliminary GLM with two variables-CPS involvement (yes/no) and was placed in care (yes/no) - will be used to test whether charge rates differ between the two groups; multilevel models are

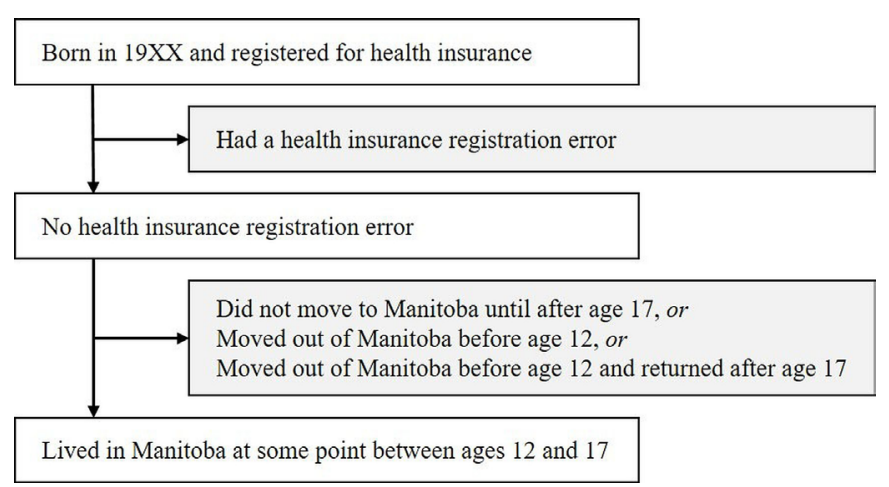

Figure 1 Birth cohort selection process. used to accommodate repeated measures over time and clustering at the family level. Then, we will construct a multivariable GLM to test whether child and family characteristics-sex, urbanicity, race/ethnicity, maternal age at birth, maternal mental health at birth, and so on-and characteristics of CPS involvement-for example, age at CPS involvement, age when taken into care, placement type or age at match date, are associated with the rate of criminal charges. We will likewise use multilevel GLMs to test whether the following characteristics among children with a history of CPS involvement will be associated with a decreased likelihood for the child to have their charge deferred: being placed in out-of-home care (vs receiving services), age at first involvement with CPS and child having diagnosed mental disorders. Finally, we will use interaction terms to test our effect modification hypotheses. 
Table 5 Categorical indicators for level of involvement with child protection services and/or the youth justice system

No involvement

with youth justice system

\begin{tabular}{ll}
\hline No CPS involvement & No involvement with either system \\
Received services from CPS & $\begin{array}{l}\text { Received services from CPS, but no } \\
\text { youth justice system involvement }\end{array}$
\end{tabular}

Spent at least 1 day in care of CPS
Was placed in care, but no youth justice Was placed in care prior to any charge and system involvement

\section{Criminal charge before turning 18}

Had a criminal charge before turning 18 , but no CPS involvement

Received services from CPS prior to any charge and had a criminal charge before turning 18

CPS, child protection services

Objective 4: examine the early adult social, education and justice outcomes of individuals involved in CPS and the youth justice system

Analyses will test whether CPS and/or youth justice system involvement prior to age 18 is associated with educational attainment (ie, high school graduation), receipt of income assistance and criminal justice system involvement as a young adult. ${ }^{18-24}$ We will use the following timevarying dichotomous indicators to classify children and youth in our cohorts:

1. The youth had a criminal charge recorded in the justice system data before their 18th birthday (yes/no).

2. The family of the child/youth was involved in CPS, but the child/youth was not in out-of-home care (yes/no).

3. The child/youth spent at least 1 day in care of CPS (yes/no).

A child with 'no' on all three indicators will have had no contact at all with CPS or the youth justice system. We will use these three time-varying indicators to construct categorical variables which will summarise each child's level of involvement with CPS and/or the youth justice system from birth to 18 years of age.

We will first generate descriptive statistics comparing the sociodemographic characteristics of the child/youth and their family (neighbourhood income, region, residential mobility, maternal marital status, maternal mental health comorbidities, child health status, and so onsee table 4 for complete list of covariates). We will test whether CPS and/or youth justice system involvement is associated with educational attainment, income assistance receipt and subsequent criminal justice involvement as a young adult. The time-varying indicator variables above will serve as the primary exposure variables in our model. The outcome variables will be high school graduation, receipt of income assistance and criminal justice involvement between ages 18 and 25. We will use GLMs with a logit link to model the association between CPS and youth justice system involvement and the odds of the three aforementioned outcomes. We will adjust for potential confounding variables such as socioeconomic status, residential mobility, urbanicity, mental health comorbidities and family-level characteristics (eg, number of children, maternal age at first birth).
All analyses will be conducted in SAS version 9.4 and significant associations identified using $95 \%$ CIs.

\section{ETHICS AND DISSEMINATION \\ Ethics}

Ethics approval was obtained from the University of Manitoba Health Research Ethics Board (No HS20344H2016:448), and the Manitoba Health Information Privacy Committee (No 2016/2017-49) reviewed the study to ensure individual Manitobans' privacy will be protected in the analyses. We have also received approval from Manitoba Health and other respective data providers for linking the administrative data in the Repository for this research programme. In order to ensure that our study aligns with ownership, control, access and possession (OCAP) and ownership, control, access and stewardship (OCAS) principles, respectively, we sought and received approval for this research from the First Nations Health and Social Secretariat of Manitoba's Health Information Research Governance Committee and from the Manitoba Metis Federation.

\section{Dissemination plan}

We are implementing an integrated knowledge translation plan to purposefully and effectively disseminate the findings from this programme of research. As discussed earlier, our plan incorporates the expertise of indigenous, government and other knowledge users and stakeholders to ensure the research findings are relevant for these groups. Knowledge mobilisation efforts to indigenous groups include the aforementioned involvement of indigenous representatives on the advisory group and on the research team with the intent to also gain additional perspectives in a workshop with indigenous youth. The Manitoba Centre for Health Policy has a long history of working closely with decision makers in government and has mechanisms in place for regular face-to-face briefings with policymakers and sharing new research findings more broadly with deputy cabinet ministers, policy analysts, service providers and practitioners in multiple sectors by hosting an annual knowledge mobilisation workshop. Through these means, we will ensure that 
key decision makers have the chance to discuss the new evidence we generate and consider how it could impact current policies and practices in child welfare and the youth justice system.

In addition, we will share our findings using traditional academic dissemination strategies, such as presenting at national and international conferences and writing manuscripts for peer-reviewed journals, as well as strategies for disseminating the results outside of academia, for example, holding a press conference and media release of the results and developing op-eds for The Conversation Canada. To connect with the public, we will prepare userfriendly lay summaries and infographics of our results for dissemination through mailings, on our website and through social media.

\section{Significance and potential impact}

Of all the provinces in Canada, Manitoba has the highest rate of children being taken into care and the highest youth incarceration rate. Strategies and efforts to address these alarming statistics and reduce the number of children in Manitoba who come into contact with the child welfare system and the youth justice system require the evidence that will be generated by this programme of research. We are working in partnership with policymakers, service providers and members of the community and have designed our research programme with their needs in mind. Our whole-population approach will generate evidence that is reflective of children's lived experiences and is not subject to the limitations that often arise from survey research in this area, such as nonresponse bias and/or lack of generalisability beyond the study sample. By working closely with our partners, we will identify and quantify the social and structural factors that predispose certain children to becoming involved with CPS and the youth justice system. This will position us to generate critical evidence that can be readily used to develop and implement the policy changes that are sorely needed.

\section{Author affiliations}

${ }^{1}$ Department of Community Health Sciences, Max Rady College of Medicine, Rady Faculty of Health Sciences, University of Manitoba, Winnipeg, Manitoba, Canada ${ }^{2}$ Faculty of Law, University of Manitoba, Winnipeg, Manitoba, Canada ${ }^{3}$ Department of Pediatrics, Stanford University, Stanford, California, USA

Acknowledgements The authors acknowledge the Manitoba Centre for Health Policy for use of data contained in the Manitoba Population Research Data Repository under project number HIPC 2016/17-49.

Contributors Led by MB, NCN and LT, all authors were involved in the conception of the research. MB, NCN and LT led the development of the study design and analyses were conducted by WA, LM and OE. All authors, including EWW, JEE, JBL, $\mathrm{SM}$ and $\mathrm{CB}$, participated in interpretation of study findings. The manuscript was drafted by NCN, EWW, LT, JEE, JBL and MB, and critically reviewed by all other authors.

Funding This research programme is supported by funds from the Manitoba Government Department of Health (Manitoba Health, Seniors and Active Living).

Disclaimer The results and conclusions are those of the authors and no official endorsement by the Manitoba Centre for Health Policy, Manitoba Health or other data providers is intended or should be inferred.
Competing interests None declared.

Patient consent for publication Not required.

Provenance and peer review Not commissioned; externally peer reviewed.

Open access This is an open access article distributed in accordance with the Creative Commons Attribution Non Commercial (CC BY-NC 4.0) license, which permits others to distribute, remix, adapt, build upon this work non-commercially, and license their derivative works on different terms, provided the original work is properly cited, appropriate credit is given, any changes made indicated, and the use is non-commercial. See: http://creativecommons.org/licenses/by-nc/4.0/.

ORCID iDs

Nathan C Nickel http://orcid.org/0000-0001-5836-5297

Jennifer Emily Enns http://orcid.org/0000-0001-7805-7582

\section{REFERENCES}

1 Turpel-Lafond ME. Joint Special Report - Kids, Crime and Care. Health and Well-Being of Children in Care: Youth Justice Experiences and Outcomes. Victoria, BC, 2009. Available: https://rcybc.ca/sites/ default/files/documents/pdf/reports_publications/kids_crime_and_ care.pdf

2 Courtney ME, Dworsky A. Early outcomes for young adults transitioning from out-of-home care in the USA. Child Fam Soc Work 2006;11:209-19.

3 Malvaso CG, Delfabbro PH, Day A. The child protection and juvenile justice nexus in Australia: a longitudinal examination of the relationship between maltreatment and offending. Child Abuse Negl 2017;64:32-46.

4 Stewart A, Livingston M, Dennison S. Transitions and turning points: examining the links between child maltreatment and juvenile offending. Child Abuse Negl 2008;32:51-66.

5 Malvaso CG, Delfabbro PH, Day A, et al. Young people under youth justice supervision with varying child protection histories: an analysis of group differences. Int J Offender Ther Comp Criminol 2019;63:159-78.

6 Stanley E. From care to custody: trajectories of children in post-war New Zealand. Youth Justice 2017;17:57-72.

7 McFarlane K. Care-criminalisation: the involvement of children in outof-home care in the new South Wales criminal justice system. Aust N Z J Criminol 2018;51:412-33.

8 Jonson-Reid M, Barth RP. From maltreatment report to juvenile incarceration: the role of child welfare services. Child Abuse Negl 2000;24:505-20.

9 Jonson-Reid M, Barth RP. From placement to prison: the path to adolescent incarceration from child welfare supervised foster or group care. Child Youth Serv Rev 2000;22:493-516.

10 Lindquist MJ, Santavirta T. Does placing children in foster care increase their adult criminality? Labour Econ 2014;31:72-83.

11 Jonson-Reid M. Exploring the relationship between child welfare intervention and juvenile corrections involvement. Am J Orthopsychiatry 2002;72:559-76.

12 Government of Canada. Backgrounder - Child and Family Services. Media Brief, 2018. Available: https://www.canada.ca/en/indigenousservices-canada/news/2018/01/media_brief_backgrounderchildfam ilyservices.html [Accessed 19 Mar 2019].

13 Statistics Canada. 2016 census data table 98-400-X2016162, 2017.

14 National Archives of Canada. Residential schools: the Indian problem. record group 10, volume 6810, file 470-2-3. , 1920: volume 7, 55-63.

15 Miller K-T, Lerchs G. The historical development of the Indian act. Ottawa, ON: Treaties and Historical Research Centre, Indian and Northern Affairs, 1978.

16 Truth and reconciliation Commission of Canada. Honouring the truth, reconciling the future: summary of the final report of the truth and reconciliation Commission of Canada. Truth and Reconciliation Commission of Canada, 2015.

17 Associate Chief Judge Edwin C Kimelman. No quiet place: final report of the review Committee on Indian and Metis adoptions and placements. Winnipeg, MB, 1985. Available: https://digitalcollection. gov.mb.ca/awweb/pdfopener?smd=1\&did=24788\& $\mathrm{md}=1$

18 Brittain M, Blackstock C. First nations child poverty: a literature review and analysis. Ottawa, ON, 2015.

19 Fallon B, Chabot M, Fluke J, et al. Placement decisions and disparities among Aboriginal children: further analysis of the Canadian incidence study of reported child abuse and neglect Part A: comparisons of the 1998 and 2003 surveys. Child Abuse Negl 2013;37:47-60. 
20 Chabot M, Fallon B, Tonmyr L, et al. Exploring alternate specifications to explain agency-level effects in placement decisions regarding Aboriginal children: further analysis of the Canadian incidence study of reported child abuse and neglect Part B. Child Abuse Negl 2013;37:61-76.

21 First Nations Child and Family Caring Society of Canada. Canada knows better and is not doing better: federal government documents show ongoing discrimination against first nations children receiving child welfare services on reserve and in the Yukon. Ottawa, on; 2015. Available: https://fncaringsociety.com/sites/default/files/ CESCR

22 Trocmé N, Knoke D, Blackstock C. Pathways to the overrepresentation of aboriginal children in Canada's child welfare system. Soc Serv Rev 2004.

23 Trocmé N, MacLaurin B, Fallon B, et al. Mesnmimk Wasatek: Catching a drop of light. Understanding the overrepresentation of First Nations children in Canada's child welfare system: An analysis of the Canadian Incidence Study of reported child abuse and neglect. Toronto, ON: Centre of Excellence for Child Welfare, 2006.

24 Ryan JP, Marshall JM, Herz D, et al. Juvenile delinquency in child welfare: investigating group home effects. Child Youth Serv Rev 2008;30:1088-99.

25 Atherton K, Fuller E, Shepherd P, et al. Loss and representativeness in a biomedical survey at age 45 years: 1958 British birth cohort. $J$ Epidemiol Community Health 2008;62:216-23.

26 Jutte DP, Roos LL, Brownell MD. Administrative record linkage as a tool for public health research. Annu Rev Public Health 2011;32:91-108.

27 Roos LL, Nicol JP, Cageorge SM. Using administrative data for longitudinal research: comparisons with primary data collection. $J$ Chronic Dis 1987:40:41-9.
28 Nickel NC, Chateau DG, Martens PJ, et al. Data resource profile: pathways to health and social equity for children (paths equity for children). Int J Epidemiol 2014;43:1438-49.

29 Statistics Canada. Focus on geography series, 2011 census, 2015. Available: https://www12.statcan.gc.ca/census-recensement/2011/ as-sa/fogs-spg/Index-eng.cfm [Accessed 4 Mar 2019].

30 Gilbert R, Fluke J, O'Donnell M, et al. Child maltreatment: variation in trends and policies in six developed countries. Lancet 2012;379:758-72.

31 Brownell M, Chartier M, Au W, et al. The educational outcomes of children in care in Manitoba. Winnipeg, MB, 2015. Available: http:// mchp-appserv.cpe.umanitoba.ca/reference//CIC_report_web.pdf

32 Legislative Assembly of Manitoba. The child and family services act. C.C.S.M. C. C80. Canada, 2019. Available: https://web2.gov.mb.ca/ laws/statutes/ccsm/_pdf.php?cap=c80

33 Government of Canada. Criminal code. R.S.C. C. C-46. Canada, 1985. Available: https://laws-lois.justice.gc.ca/PDF/C-46.pdf

34 Government of Canada. Young offenders act. Repealed, 2002, C. 1, S. 199. Canada, 2003.

35 Tustin L, Lutes R. A guide to the youth criminal justice act. Toronto: LexisNexis Canada, 2019.

36 Legislative Assembly of Manitoba. Youth criminal justice act. SCc1. Canada, 2002. Available: https://laws-lois.justice.gc.ca/PDF/2002_1. pdf

37 The Johns Hopkins University, Weiner JP, ed. Bloomberg School of Public Health.The Johns Hopkins ACG Case-Mix System Documentation \& Application Manual. Version 10. Baltimore, MD: Johns Hopkins University, 2001.

38 Statistics Canada. Aboriginal population profile. 2006 census, 2006. 